\title{
Espacio marítimo y de montaña. La costa de Granada y sus valores patrimoniales
}

\author{
Antonio Malpica Cuello | Universidad de Granada \\ URL de la contribución <www.iaph.es/revistaph/index.php/revistaph/article/view/3608>
}

\section{RESUMEN}

La costa de Granada es un territorio definido por dos características básicas: el mar, como no podía ser de otra manera, y un abrupta montaña, que a veces cae directamente sobre él. Por su realidad física puede presentar dificultades para el asentamiento de poblaciones, pero tiene los elementos suficientes, e incluso más, para la instalación de gente y para la recepción de foráneos. Desde fechas tempranas se han ido asentando pobladores que le han dado un carácter abierto y que le han permitido instalar innovadoras formas de vida. Se estableció un mecanismo productivo muy rico, gracias al cultivo de áreas bajas y con importantes sedimentos, y también al aprovechamiento de la riqueza pesquera y marítima.

Está dividida en varias zonas. De la más oriental, que ocupa las sierras de la Contraviesa y Lújar, con pocos espacios llanos y con un poblamiento esencialmente rural, se pasa a la zona media, centrada en el delta del Guadalfeo, siendo Salobreña el punto más importante, para llegar al límite con el área malagueña, en la parte occidental costera granadina, con Almuñécar como la ciudad de todo el conjunto.

Las formas de vida han dejado su huella en el paisaje actual. De la época antigua hay numerosos testimonios, destacando las villae romanas y las construcciones públicas sexitanas; de la medieval, las fortificaciones que jalonan la línea marítima; y de los tiempos modernos y contemporáneos, el azúcar desarrolla una historia en la que la producción industrial alcanza su punto más elevado. Este paisaje conforma un verdadero patrimonio entre el mar y la montaña.

\section{Palabras clave}

Agricultura | Caña de azúcar | Cordilleras béticas | Costa de Granada | Cultivo industrial | Ganadería | Minería | Paisaje cultural | Pesca | Territorio | 


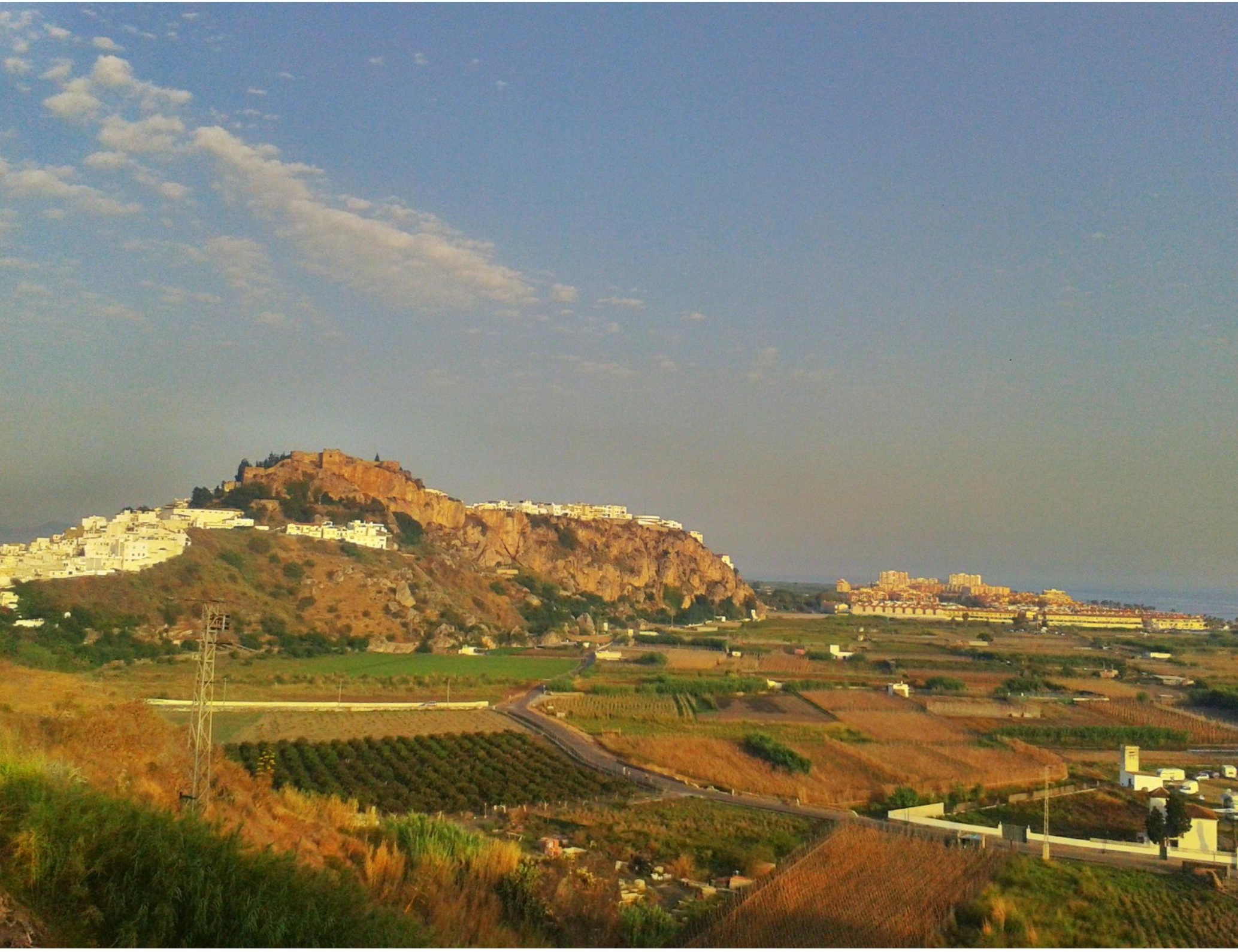

Castillo de Salobreña | foto Isabel Rivera 
1

"De allí a Marsà al-Firrūŷ, pequeño puerto como un estanque, 12 millas" (Idrīsī, Description de l'Afrique et de l'Espagne, edición de texto árabe y traducción francesa de Dozy, Reinhardt P. A. y de Goeje, Michäel, Leiden, 1866, reimpresión, Amsterdam, 1969, p. 199 del texto árabe y p. 242 de la traducción francesa.
Un montaña de cierta altura con cumbres que pueden superar los $1.500 \mathrm{~m}$ y alcanzar más de 2.000 m se levanta a poca distancia de la línea marítima. Esta cadena costera tiene una personalidad en su conjunto, integrado en las Cordilleras Béticas litorales. Ahora bien, se halla dividida en sierras con características particularidades cada una de ellas.

Aun cuando trataremos de las que se adscriben a la llamada costa de Granada, área con una entidad propia, parece obligado trazar una primera panorámica general. De este a oeste, encontramos las Sierras Alhamilla, Gádor, Contraviesa, Lújar, Almijara y Tejeda, así como un grupo montañoso en Málaga de mayor complejidad.

La cercanía de la montaña al mar ha configurado una costa muy recortada y en buena medida abrupta, aunque podemos hacer distinciones que han de ser puestas de manifiesto. Así, en el tramo almeriense, las sierras están más alejadas y existen llanuras amplias, destacando el Campo de Dalías, el valle del Andarax, en el entorno de la capital, Almería, y el Campo de Níjar, precursor del área de Cabo de Gata.

En el granadino, las elevaciones están muy próximas a la línea marítima, de manera que a partir de Adra, en el extremo occidental de la actual provincia de Almería, hasta Nerja, en el límite oriental de la malagueña, la montaña cae directamente al mar, formando acantilados que hacen muy difícil el paso de un lugar a otro; a veces es preferible usar barcos para moverse que intentarlo por tierra. Los pocos espacios llanos que hay son deltas y minúsculas calas, hasta el punto que la hoya litoral generada por el río Guadalfeo es la más importante en esta área granadina. Hacia levante hay minúsculas llanuras, siendo la más importante la de Castell de Ferro, ocupada desde fechas antiguas y a cuyo embarcadero se refiere Idrīsī en el siglo XII ${ }^{1}$. Está formada por la colmatación hecha por las ramblas de Gualchos y Lújar. Si avanzamos a poniente del delta del Guadalfeo, en donde se encuentran Motril y Salobreña, esta última población muy antigua, llegamos a Almuñécar, el núcleo con una historia más extensa y densa de toda la costa granadina, que ocupa un peñón sobre el mar, al final de una llanura deltaica, formada por los aportes de los ríos Verde y Seco.

En el sector malagueño, de Nerja a Gibraltar, encontramos una montaña próxima a la costa, si bien con áreas alejadas del mar, entre las que destaca la llanura formada por el río Guadalhorce.

En las partes llanas, se ha concentrado buena parte de la gente que ha vivido en la costa mediterránea andaluza a lo largo de la historia. No es menos cierto, sin embargo, que la agricultura mejor representada en ellas es la de regadío, aunque fue necesario una operación constante de saneamiento para evitar los encharcamientos más o menos permanentes; también 


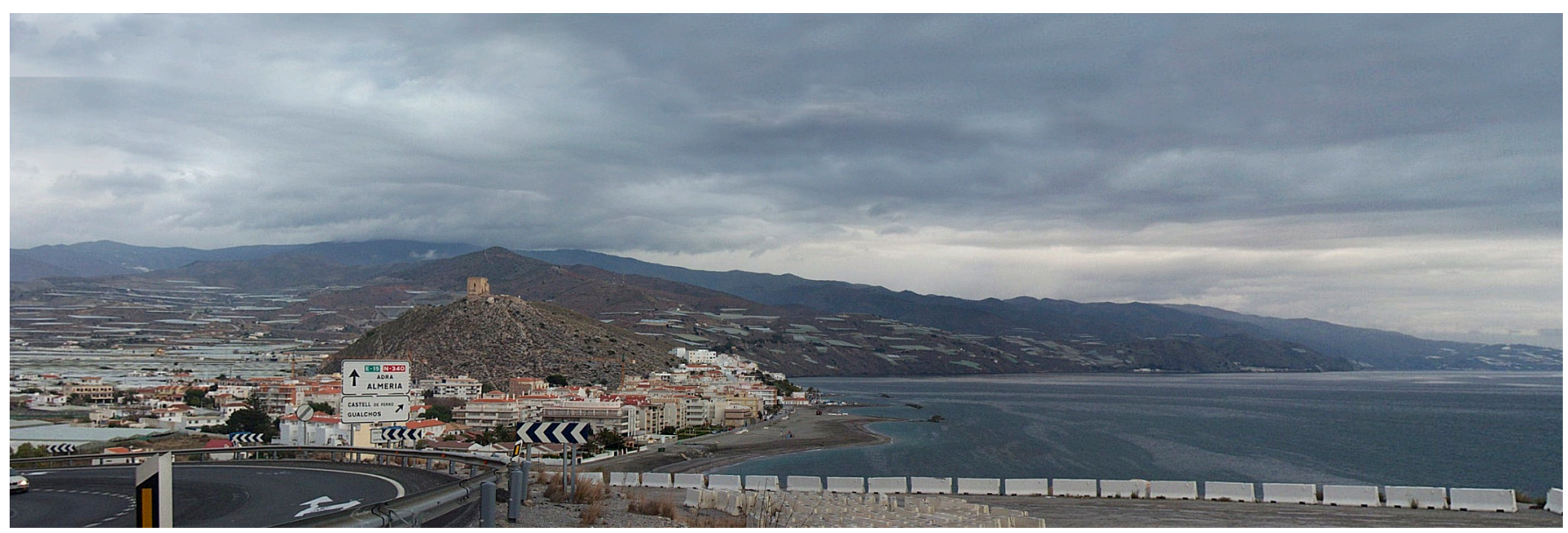

Castell de Ferro | foto Fondo Gráfico IAPH (Silvia Fernández Cacho)

está presente, desde antiguo y por necesidad de escapar de las inundaciones, en las colinas que sirven de contacto con la llanura y en las elevaciones en las que la composición litológica lo permitía.

Sin duda la acción de los cursos de agua, a veces espasmódicos e indomables, como corresponde a un régimen de lluvias plenamente mediterráneo, ha influido en la organización de los espacios de cultivo, así como las roturaciones y una continua pérdida de la cubierta vegetal por la presión de las actividades humanas, con picos importantes, han permitido una erosión que alcanza momentos paroxísticos con aluvionamientos que han generado suelos más o menos profundos en las áreas llanas, con sedimentos de mucha profundidad.

Así pues, la relación montaña-llanura-litoral es muy importante y en ella tiene un papel destacado el movimiento del substrato litológico, tan relacionado con la dinámica de la vegetación, de la que habrá que hablar aunque sea someramente.

Si bien hemos de decir que esta montaña es una cadena litoral que forma un farallón que protege las tierras costeras de los vientos fríos del norte y crea así unas condiciones climatológicas muy buenas, con insolación, temperaturas muy dulces atemperadas por el mar y suficiente agua procedente de las cumbres y de las faldas de las sierras, tiene características propias de las elevaciones.

Hay que pensar, eso sí, en las dificultades que se plantean para seguir y desarrollar una ruta longitudinal. Por eso se emplea la navegación como medio de desplazarse de un punto a otro. En cualquier caso, cada sierra se halla separada de las otras por pasillos que permiten el drenaje de las aguas de las elevaciones, así como la comunicación con las tierras intermedias del 
surco intrabético. No todos los pasos existentes tienen la misma entidad. Se han de citar tres como los más importantes. El situado más al este, sin hablar por tanto del valle del Almanzora, es el denominado Pasillo de Fiñana, entre la Sierra de Baza y la Nevada, que progresa hacia el sur por el río Nacimiento, que se une con el Andarax. Es de este modo como se produce la división ya cerca de la costa entre Sierra Alhamilla, al este, y la Sierra de Gádor, al oeste, quedando la ciudad de Almería entre ambas. Antes de llegar a esta ciudad y después de unirse por la margen derecha del Andarax el Nacimiento a él, por la parte izquierda se abre un eje de comunicación que bordea Sierra Alhamilla por su cara norte y llega a Tabernas, desde donde progresa hasta integrarse en el citado pasillo.

El siguiente, si seguimos en dirección a poniente, es el formado por el valle de Lecrín. Una serie de cursos de agua se van uniendo hasta integrar todos el río Ízbor, afluente del Guadalfeo por su margen derecha. Este último viene del sinclinal formado entre la cara sur de Sierra Nevada y la cadena litoral. No se abre con facilidad ni hacia el sur, camino de la costa, ni tampoco hacia el este para llegar a la Alpujarra. Viniendo de la Vega de Granada y del Quempe, este último enlace con la tierra de Alhama, se ha de pasar el puerto del Suspiro del Moro para progresar hacia el sur, pero no reviste en tal caso una dificultad digna de tenerse en cuenta. Es mucho más angosto el camino, como ya se ha dicho, hacia la costa y la Alpujarra, pues si seguimos el río Ízbor la vía es muy dificultosa. Hasta tal punto es así que se solía utilizar de manera preferente el camino que va por Restábal y llegaba hasta el río de la Toba, en donde se encontraban los núcleos llamados Los Guájares. Si se continúa por ese curso de agua, se alcanza el Tajo de los Vados, por donde se podía cruzar el Guadalfeo y situarse en la llanura litoral de Motril y Salobreña.

Contamos asimismo, ya en el espacio malagueño, con el camino que forma el valle del Guadalhorce. Es un eje de comunicación entre la depresión de Antequera y la costa situada inmediatamente al oeste de Málaga. Organiza la Algarbía, llamada así por estar a poniente de la ciudad, contigua a ella.

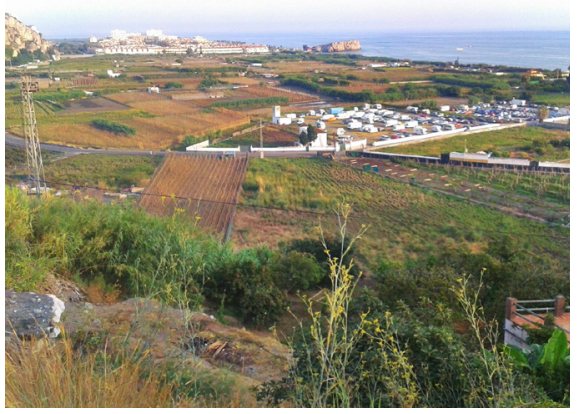

Vega de Salobreña | foto Isabel Rivera

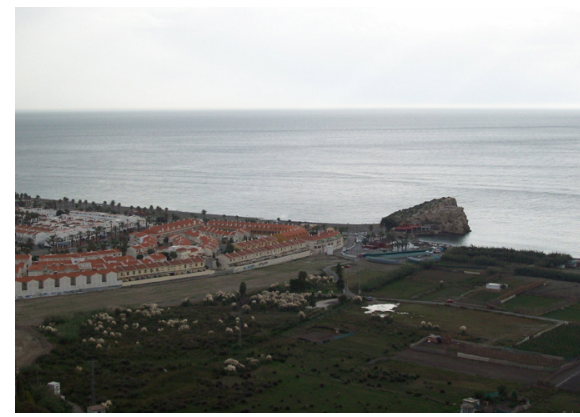

Playa de Salobreña | foto Ana M. a López 
Se ha de hablar de un origen doble de estos pasos. De un lado es tectónico, por fallas que se produjeron a causa de los reajustes con la formación de pliegues de fondo; de otro, responde a reajustes isostáticos fruto de la necesaria compensación entre bloques que se levantan y otros que se hunden por el peso de los materiales depositados a causa de la erosión.

Teniendo en cuenta la topografía del territorio y su geología, este espacio tiene unas características ya señaladas, pero en las que hay que insistir. Ante todo se advierte una relación muy directa entre las distintas áreas, la montañosa y la llana, con respecto a la formación de los suelos. La pendiente ocasiona una erosión sobre todo cuando no hay una potente cubierta vegetal. El ritmo y la mayor o menor capacidad erosiva depende esencialmente de ella y de su evolución a lo largo del tiempo. La capacidad erosiva de ramblas, torrentes, arroyos y ríos ha sido variable en el transcurso del tiempo. Si atendemos a la desnudez o no de la montaña tendremos un primer elemento de análisis, pero asimismo hay que conocer la pendiente y su gradiente.

Los estudios de algunos espacios costeros no dejan lugar a dudas sobre el hecho de que el crecimiento de los suelos en las tierras llanas se debe en buena medida a los aportes de los aluviones procedentes de las áreas elevadas. Ahora bien, el componente litológico es muy importante para poder calcular su evolución y la acción de los agentes erosivos, así como la mecánica que presentan.

Los que tienen un componente calcáreo se han ido transformando por procesos erosivos y han llegado a estar desnudos. Es difícil encontrar áreas con un conjunto vegetal maduro. Por otra parte, estas rocas tienen una gran capacidad de absorber agua y, así, en su interior, hay depósitos subterráneos capaces de almacenarla, existiendo grandes capas freáticas que permiten suministrarla a tierras, animales y hombres.

Los compuestos por rocas metamórficas, como los esquistos, micaesquistos, filitas, etc., son impermeables, lo que hace posible que circule el agua por la superficie. La erosión que han ido sufriendo al perder su cubierta vegetal ha hecho que la roca madre tenga importantes alteraciones, que se ven acentuadas por las considerables pendientes que existen. De esa forma es como se han ido formando suelos con gruesas piedras por las transformaciones mecánicas que han padecido. El campesino se ha visto obligado a una lucha constante con el medio.

La relación entre la pérdida de la cubierta vegetal, que en varios puntos era todavía, tras la conquista castellana, madura, con alcornocales y encinares, de lo que quedan algunos restos, y los aluvionamientos es un proceso histórico, en el que, por tanto, la mano del ser humano ha sido importante. Sería 


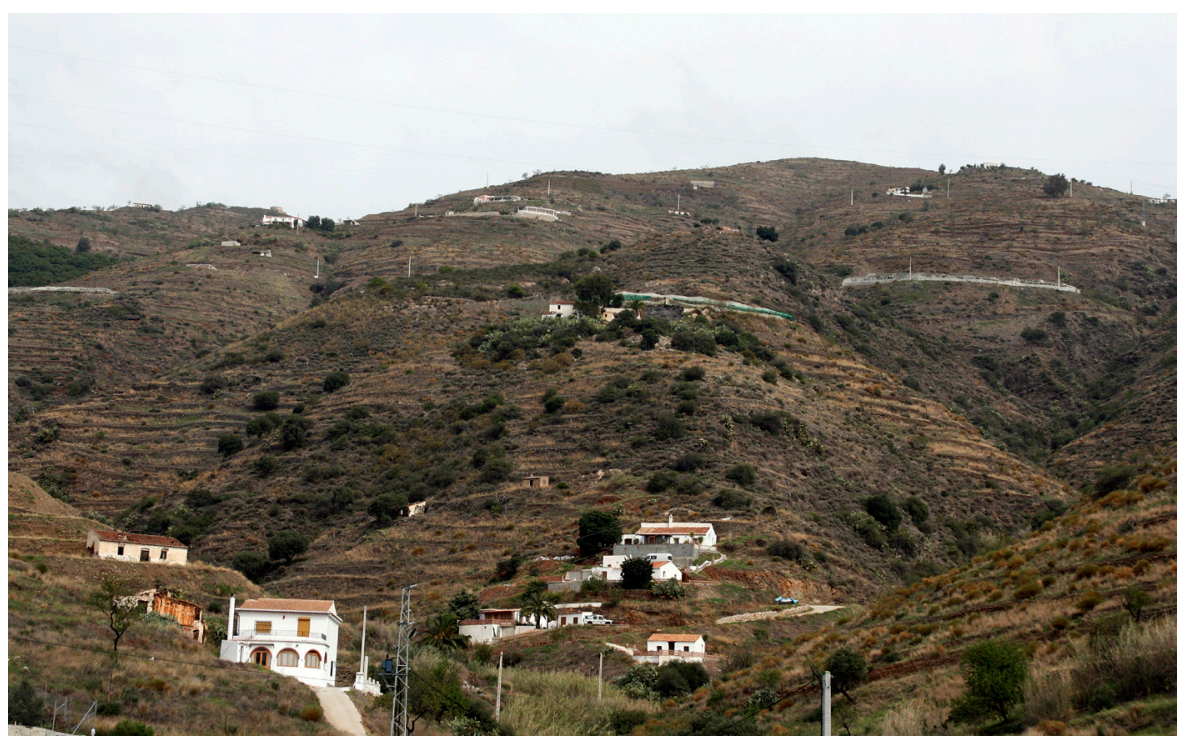

Entorno de Salobreña | foto Fondo Gráfico IAPH (Víctor Fernández Salinas)

necesario conocer esa dinámica que tiene sus períodos históricos más o menos perfilados. En época medieval, por tanto andalusí, la organización del territorio determinaba la existencia de áreas bien definidas agrícolamente, con tierras irrigadas, bien aterrazadas en el entorno de los barrancos que se alimentaban de fuentes, bien en el llano, con una pendiente mucho menor. El dominio del monte mediterráneo en el medio natural era importante, como lo era la vegetación de ribera.

Con posterioridad a la conquista castellana y a una primera ocupación, la producción azucarera, que ocupa una línea productiva de primera magnitud en la vida agraria costera, supuso un inmediato y gigantesco consumo de leña para los ingenios. En ellos se elaboraba el líquido resultante de la molienda y prensado de la caña que se había de calentar para conseguir la concentración de sacarosa que luego cristalizaba en conos de barro. Este crecimiento fue aumentando hasta pasar verdaderas dificultades para conseguir leña. Posteriormente la construcción naval y ya en el siglo XIX la minería hicieron aumentar el consumo de madera y leña.

Pese a no haberse estudiado este tema a fondo, podemos afirmar que la pérdida de cubierta vegetal empezó a ser "crítica" a partir del avance de la producción de azúcar. Los efectos constantes sobre el paisaje se constatan desde el siglo XVII en adelante.

Los cambios se perciben en toda la cadena costera, con especial incidencia en los territorios en que la caña y las explotaciones mineras fueron mayores. Pero en todos los casos se asiste a un proceso roturador, cada vez mayor, en la medida en que los espacios cultivados en el llano se dedican a una 
agricultura de monocultivo, sobre todo de caña de azúcar primero y de otros cultivos, hasta llegar más recientemente a los productos de huerta.

Ahora bien, la cadena montañosa combina formas de vida agrícola con otras a las que no se les ha prestado la atención debida. Debemos fijarnos en el uso multiforme del terreno. Cierto es que la agricultura es capital, con transformaciones ya enunciadas, pero su indudable variedad y su evolución no ocultan la ocupación de tierras por el ganado, el aprovechamiento de recursos naturales como, por ejemplo, las salinas, la dedicación a la pesca y a otras actividades que usan el conjunto territorial. Su organización fue variando al compás de las transformaciones históricas que han conducido a la situación actual. Todo esto merece un comentario un poco más extenso.

En realidad no se puede hablar propiamente de una alta montaña, porque los asentamientos no se sitúan nunca a los $2.000 \mathrm{~m}$, si bien hay frecuentación, sobre todo de los pastos, y alguna vida agrícola en la que se cultivaban cereales de tierras más frías.

Por otra parte, las llanuras no han sido siempre espacios saneados, antes bien ha sido necesario un largo proceso, con avances y retrocesos, para salvar los encharcamientos e incluso la dinámica lagunar en algunos puntos. El juego combinado de las corrientes marinas contiguas y vientos, junto con el aporte de agua de los cursos más o menos permanentes y de los esporádicos, a veces muy violentos, ha ido configurando espacios firmes, reservando aquellos que tenían buenas condiciones para la vida agrícola y dejando de lado los que presentaban más dificultades para su saneamiento. Por eso mismo, encontramos junto a tierras de cultivo muy fértiles con suelos profundos, otros anegados y apenas fijados, e incluso explotaciones salineras. Este proceso no se ha analizado de forma integral, a veces ni siquiera conveniente. Tal vez la primera cuestión que haya que plantearse sea la fijación de los cursos de agua. Si se estudiara, por ejemplo, de manera inteligente, el proceso que ha sufrido el río Guadalfeo, el único merecedor realmente de tal nombre en la costa de Granada, se advertiría que la sujeción de las riberas se hizo con vegetación plantada para tal fin, tal vez en diferentes períodos históricos, pero sobre todo a partir del siglo XIX, cuando los efectos de una permanente e imparable erosión de las colinas y montañas de su cuenca se dejaron sentir de manera violenta. Es lo que se aprecia, sin ir más lejos, en la ruina de las tierras de Pataura, a poco de salir del Tajo de los Vados, y en el hecho de que la población fuese sepultada por una riada. Para la fijación del cauce no solo se procedió a plantar árboles, sino que también se aprovecharon espacios húmedos para cultivar arroz y en área bajas, caña de azúcar. Posiblemente haya que pensar en sistemas de regulación de las aguas a través de las acequias que permitían regar tierras de otros puntos, pero también evitar un flujo excesivo del cauce. Es lo que parece percibirse, por

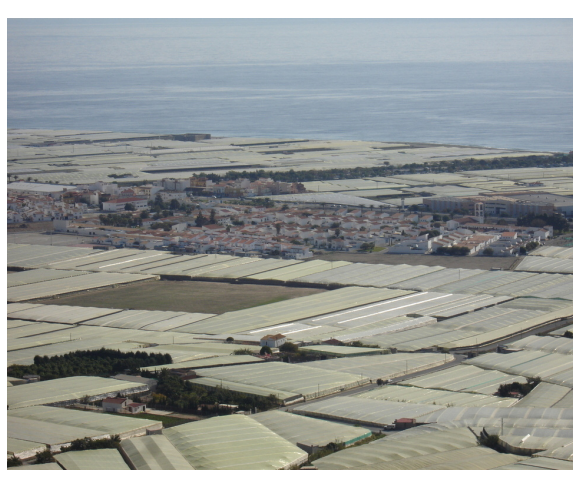

Carchuna. La agricultura marca el ritmo de crecimiento económico de este pueblo y tiene su punto de inflexión en el desarrollo de la agricultura intensiva bajo plástico | foto Fondo Gráfico IAPH (David Arrendo Garrido, Alberto García Moreno) 
seguir con el caso del Guadalfeo, en el caso de las acequias de Salobreña, por la margen derecha, y de Motril, por la izquierda; esta última llevando el agua bastante lejos del eje del río.

De ese modo, tenemos un territorio configurado de manera compleja. No solo por la existencia de diferentes líneas productivas: agricultura, ganadería y aprovechamiento de recursos marítimos y terrestres, sino también con diferentes grados de intensidad en los cultivos y en la cría de ganado. Es así como hay productos de huerta y cultivo intensivo que se puede considerar en algunos momentos industrial, tal y como la caña de azúcar, pero también secanos de ladera (higueras, viñas, cereales, etc.), con una capacidad alimentaria y comercial de indudable importancia. En algunos momentos parece que se da una dualidad entre tierras dedicadas a la producción casi exclusivamente comercial y otras destinadas principalmente a la alimentación de las poblaciones que allí habitan. Lo que ocurre es que esa aparente dualidad se corrompe, puesto que en ciertos momentos, como a finales del período medieval y en los primeros tiempos modernos, el desarrollo de las actividades comerciales parece ganar la partida que se estaba jugando. Claro está que las condiciones sociales lo permitían, toda vez que una población sometida y muy controlada era una mano de obra imprescindible para tales operaciones.

La ganadería, muy necesaria en algunos momentos por el gran desarrollo agrícola que vive dos picos (el posterior a la conquista castellana y el generado en el siglo XVIII con una colonización creciente de las colinas y aun de la montaña), tiene su papel en cada área del territorio. Sin duda los pastos de media montaña, en algunos puntos favorecidos por los manantiales existentes, contribuían a sacar los ganados de los espacios llanos, en donde la alta capacidad productiva de los campos aconsejaban su preservación de la conocida voracidad de los herbívoros. Pero no es menos cierto que los espacios bajos, a veces anegados, posibilitaban que caminasen los hatos por allí y se alimentasen.

Esa permanente acción sobre el medio no ha sido definitiva hasta fechas relativamente recientes, quizás por la necesidad de emprender grandes obras de saneamiento y control y la escasez de población suficiente. La insalubridad de las zonas bajas determinó que hubiese un serio obstáculo para que se instalase en cifras adecuadas. Pese a ello, la vida marítima, una gran desconocida, completó la frecuentación de alguna gente. La misma configuración de la línea costera, como se ha dicho recortada y abrupta, generó una ocupación ocasional y en modo alguno permanente. La explotación de la pesca era estacional, aprovechando a veces las costumbres migratorias de determinados peces, como túnidos y escómbridos. Se establecen pesquerías, que no se usan siempre, pero que están activadas en determinadas fechas. 
Toda la configuración que venimos describiendo explica el control del conjunto territorial y las formas en que el poder estatal se ha ido apropiando de los excedentes productivos. Así, tenemos una imagen espacial e incluso arquitectónica de los diferentes proyectos estatales para él. La mayor o menor acción del Estado ha ido dejando huellas más o menos visible que se reconocen arqueológicamente sin mucho esfuerzo.

Aun a riesgo de reducir esta y otras cuestiones, parece necesario hacer un breve resumen de las etapas que se pueden reconocer. Desde fechas tempranas hay asentamientos que nos hablan de la puesta en valor de los recursos naturales. Entre ellos, cómo no, los del mar. Así, tenemos establecimientos desde el Neolítico que usan las posibilidades pesqueras y recolectoras del mar (Melicena y La Rijana, por ejemplo), pero también hay una ocupación en cuevas de entidad, con una jerarquización social a veces muy marcada (Cueva de los Murciélagos, en Albuñol), y un aprovechamiento de espacios agrícolas y ganaderos (Cueva del Capitán, en Lobres).

Hay también una explotación de minerales, con prospectores que van recorriendo el conjunto territorial y usando en su beneficio tales recursos que los concentraban en puntos más alejados. Los efectos de tales actividades han dejado huellas, con pequeños yacimientos que explican el conocimiento del medio, según se observa en el cortijo de la Rehala, por encima de Carchuna, y en el entorno de Polopos, por poner ejemplos en los que es posible distinguir la proximidad de las vetas de minerales.

En la misma línea costera se fueron creando núcleos de mayor entidad conectados con los interiores y en relación con los colonizadores fenicios, y luego púnicos, que generaron una jerarquización social importante, con distinciones apreciables. Han dejado restos de extraordinaria importancia, como los existentes en Almuñécar, la antigua Sexi, que nos muestran relaciones fluidas con las grandes culturas del Mediterráneo y una serie de bienes patrimoniales de primera entidad. De menor valor pueden considerarse los restos que se aprecian en el borde costero. Ponen de manifiesto una constante frecuentación marítima, así como la explotación pesquera y salinera. El peñón exterior de Salobreña puede ser un ejemplo. El garum hace su aparición de manera constante y significa la integración de la costa granadina en el conjunto mediterráneo. Sin duda eso debió de hacer florecer una jerarquía social autóctona protegida por los colonizadores, que se percibe con claridad en los ajuares con que se entierran.

Este esquema de relación se desarrolló en época romana hasta procederse a una integración plena. El valor de las tierras interiores se fue desarrollando al compás del avance de la penetración romana. No solo se identifican explotaciones agrícolas de mayor o menor extensión, sino también asentamientos en relación con la minería en puntos de la montaña

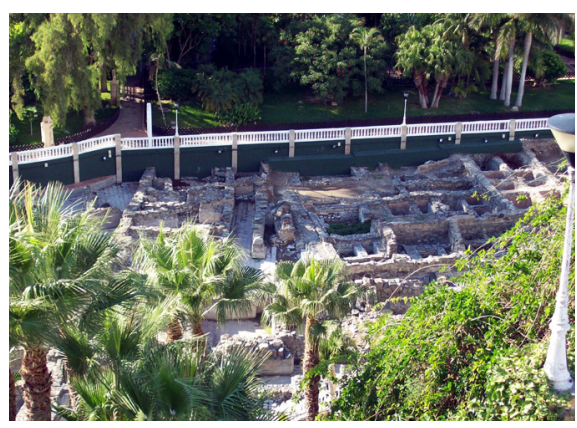

Factoría de salazones de Almuñécar | foto Ana M. ${ }^{a}$ López 
en donde principalmente se conseguía galena argentífera desde épocas anteriores.

A partir de tales fechas la capacidad productiva en sus diferentes niveles, que no solo la fabricación de garum, con ser muy importante y manifestar la importancia de la pesca de la costa y de la sal marina, se expresa en toda su intensidad.

La acción estatal, que permite la unión e integración de la franja costera con el conjunto del mar Mediterráneo, y un comercio regular, dejó huellas muy notables en todo el espacio en cuestión. Marcó de manera indeleble el territorio, pero sobre todo jerarquizó los asentamientos. A la cabeza de todos se hallaba Almuñécar, municipium sexitano, que quedó configurada como una auténtica ciudad romana. Los monumentos de esa época la ornaron, no solo en su interior amurallado, sino fuera del mismo, siendo un magnífico ejemplo el acueducto. La capacidad productiva de ella queda de manifiesto en su factoría de salazones.

Sin duda la aristocracia romana controlaba todo el conjunto espacial, con la existencia de villae y otros asentamientos que marcaban el carácter del mismo y señalaban bien a la claras la inserción global en el Imperio romano.

La importancia patrimonial de la costa creció progresivamente de manera notable y ofrece un cuadro de primera magnitud. Sin embargo, la crisis de

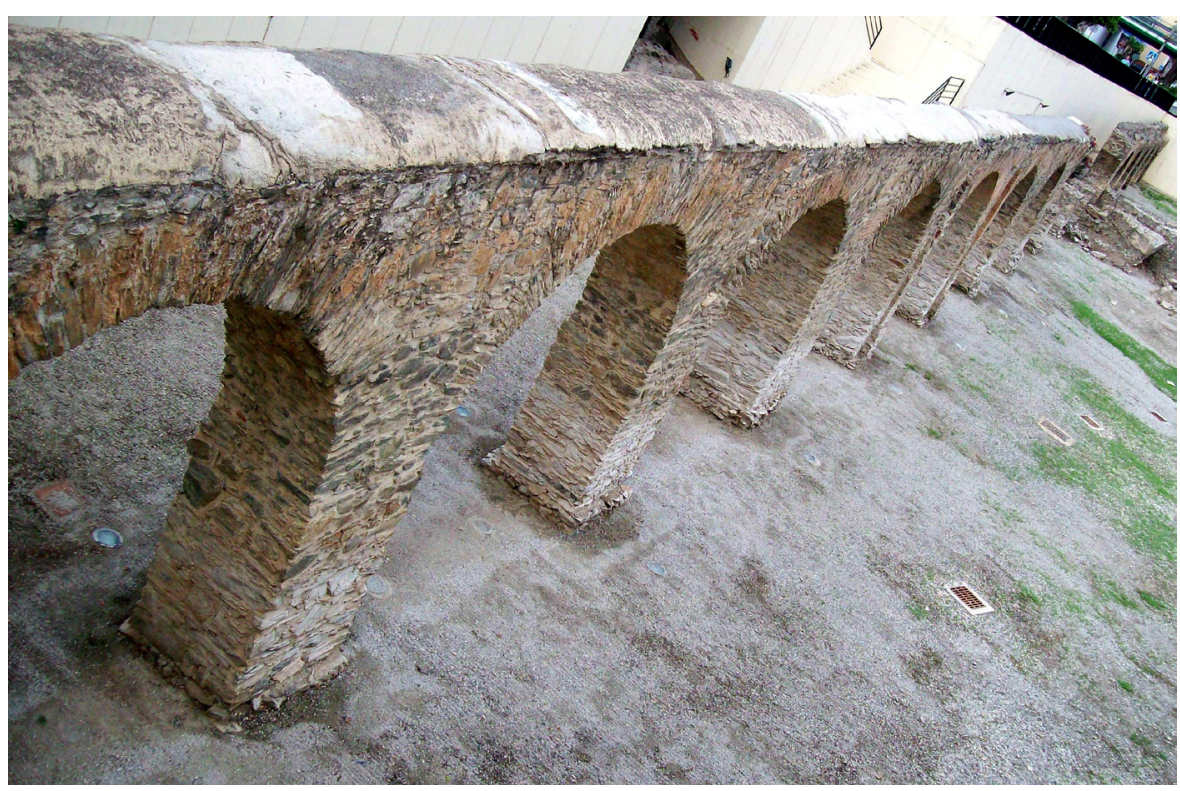

Acueducto romano de Almuñécar | foto Ana M. ${ }^{a}$ López 
las estructuras políticas a partir del siglo III y en adelante destruyó los nexos de relación. La ruptura de las redes de unión supuso un enrarecimiento de las comunicaciones y una pérdida de los valores urbanos a favor de una creciente ruralización.

De esa manera, cuando los árabes llegan a la Península y se establecen en la costa, la vida urbana es casi un recuerdo. Los núcleos existentes están desestructurados, los espacios no llegan a estar regidos por la ciudad, salvo la escasa influencia de Almuñécar y la prácticamente nula presencia de Salobreña. En el este ya no hay ciudades. Así se configuran unas áreas que resaltan con características propias. Podemos distinguir de este a oeste las que siguen:

> Las țā'a/s de Sāḥil y Suḥayl, si empleamos la denominación de época nazarí, o sea a finales del período andalusí, ocupan el espacio, respectivamente, de la Sierra de la Contraviesa y de la Sierra de Lújar. Mientras en la primera los materiales metamórficos son los dominantes, con elevaciones no demasiado altas ni tampoco con formas abruptas, en las segunda se aprecia un relieve escarpado de componentes calizos. Así en estas es posible encontrar capas subterráneas de agua que afloran a veces de forma natural (caso de Vélez-Benaudalla) o por medio de galerías hechas por manos humanas y permiten concentrar la irrigación en determinados puntos, sobre todo en aquellos en que la base litológica lo permite por la relación de mantos geológicos, mientras en la Contraviesa hay un número disperso de fuentes que hacen posible un cultivo que esmalta el paisaje.

Los paisajes rurales, que impregnan todo el conjunto, fueron en tiempos andalusíes pequeños núcleos dependientes de puntos de agua concentrados o no, con un área de cultivo irrigada que destacaba en el espacio y que se hallaba en el entorno del asentamiento. Más allá encontramos bien un secano ocasional, bien una vegetación espontánea propia del monte mediterráneo. La densidad de ocupación humana no es muy grande, si bien aumentó a partir del siglo XVIII, cuando se explota la tierra con mayor intensidad, y se puebla de cortijos que llevan el nombre de las familias que los conforman. En todo caso, la producción ganadera está muy presente y se puede hablar de una tierra dedicada al ganado. En el borde costero, muy recortado, hablamos de la pesca y de la vida marítima que significa asimismo la posibilidad de comerciar por medio de barcas, extrayendo los productos procedentes de los asentamientos agrícolas interiores.

Estos núcleos disminuyeron tras la llegada de los castellanos y quedaron prácticamente desiertos, ocupados por la familia de los Zapata que crearon un Estado señorial con base en Torvizcón. Se formó una suerte de espacio militarizado con escasa población que iba de un lugar a otro para realizar las actividades necesarias de una agricultura que, aunque no intensiva, mante- 
nía un cierto nivel, sobre todo en árboles como las higueras y en arbustos como las vides, en el secano.

En esas fechas se produjo una verdadera transformación de los mecanismos defensivos. Desde tiempos califales (siglo $\mathrm{X}$ ) asistimos a un proceso de fortificación de la costa con la creación de torres y castillos, pero sobre todo con el amurallamiento urbano, posiblemente para asegurar su posesión y evitar los problemas con los fatimíes que progresaban por la orilla sur del Mediterráneo. Los sistemas defensivos continuaron existiendo e incluso se adaptaron en tiempos sucesivos, siendo en época nazarí, si no ya en la almohade, el momento en que se fortificó la línea costera, se protegieron las llanuras aluviales y también las calas en donde los barcos hacían escalas y en las que se pescaba. A partir de esa línea de defensa se reordenaron los edificios castrales y se fortalecieron. Algunos de los castillos existentes se quedaron como elementos sustanciales para el control del territorio, en un doble sentido, en cuanto era necesario sujetar a la población vencida, de un lado, y, de otro, ante los ataques piráticos. Ambas cosas se unían a veces, llegando a vaciarse de población en un porcentaje superior a la mitad de los núcleos. Esos castillos (La Rábita y Castell de Ferro, al borde del mar) fueron importantes para reforzar la defensa y evitar desembarcos en las playas y su progreso hacia el interior siguiendo las ramblas, al final de las cuales se encontraban.

Fue necesario una política de guerra que fue en aumento hasta alcanzar instantes paroxísticos de violencia. Solo a partir del siglo XVIII se produjo una reconversión, poblándose de nuevo las tierras interiores, ahora creciendo por medio de cortijos que se aprovechaban de puntos de agua y de condiciones litológicas para el cultivo de sus suelos. Se prefirieron los de secano, con una extensión de las vides, hasta el extremo de ser casi únicas, pero también de higueras, cereales y, en menor extensión, olivares. El ganado continuó siendo importante. Las fuentes escritas distinguen entre las tierras irrigadas, de las que se podían obtener cosechas regulares, y las que no recibían agua, en las que la producción agrícola era más escasa y estaba distanciada en el tiempo.

También la línea de costa se ocupó, si bien en menor cuantía poblacional en cuanto al número de gente y de asentamientos. Para ello fue necesario fortificarla de nuevo. Es entonces cuando aparecen castilletes como los que se ven, por ejemplo, en el Castillo de Baños, o se transforma alguno como el de La Rábita que se nos aparece como un edificio dieciochesco. Paralelamente se construyeron torres de planta circular y desarrollo troconónico que ayudaron a la seguridad costera y de sus poblaciones inmediatas o no.

Esa imagen pervive hasta fechas recientes, que podemos cifrar en los años 70 del siglo XX, cuando se produjo una gran concentración en la costa y 


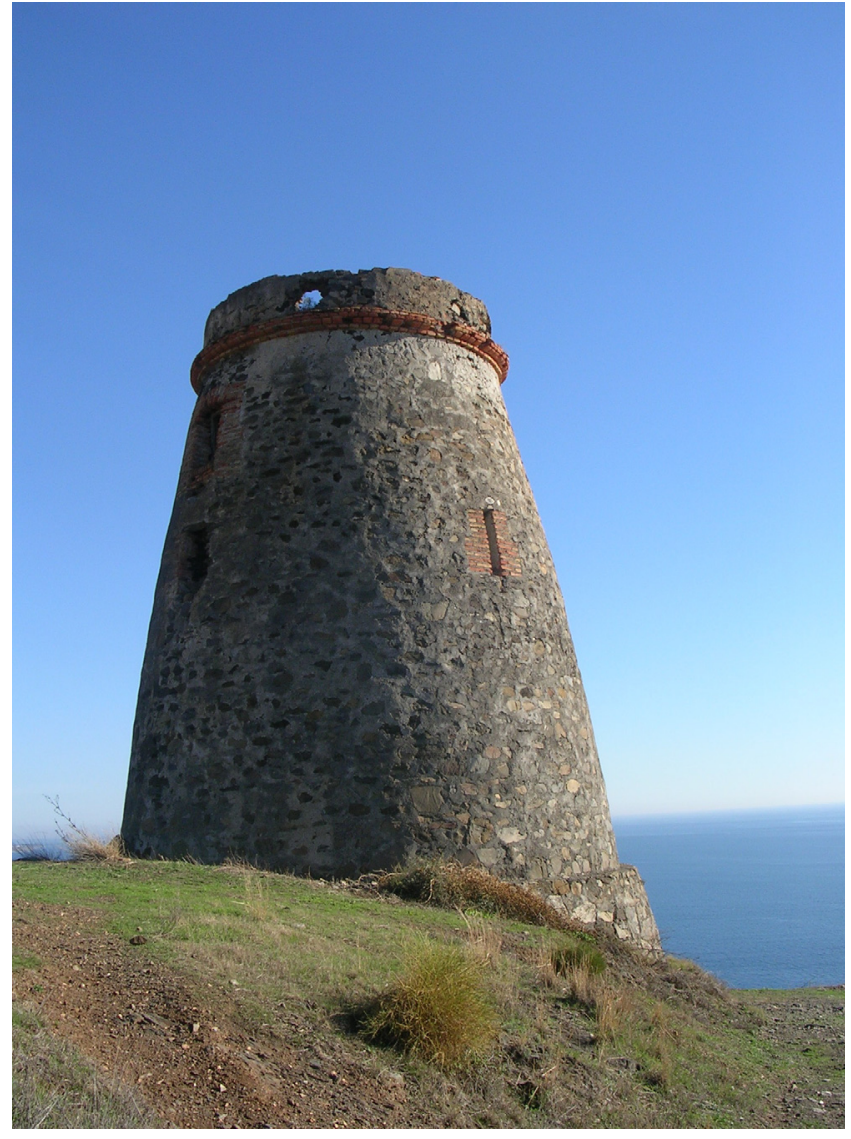

un despoblamiento de las tierras interiores que casi llegaron a vaciarse. La agricultura de invernaderos ha transformado radicalmente el medio y ha hecho crecer la explotación de la tierra y del agua hasta extremos insospechados, de tal manera que hoy entramos en una etapa de futuro incierto, cuyo balance ha podido ser un enriquecimiento de la población, una igualación social, pero asimismo la pérdida de los valores culturales tradicionales y de las formas de vida anteriores, sin que haya habido una sustitución equivalente. El abandono de todos ellos ha traído consigo una separación tajante de la historia y de la geografía, con una ruina de los bienes patrimoniales que no pasan por su mejor momento, como se puede ver en la fechoría cometida, por ejemplo, en el castillo de Castell de Ferro, cuya recuperación se emprendió y ha quedado sumido en el abandono más insultante.

> La hoya litoral de Motril y Salobreña, organizada por el eje del Guadalfeo, es el espacio central de la costa granadina. Es la llanura más significativa de todas y, desde luego, eso le ha permitido ir ganando en importancia conforme ha avanzado el tiempo.
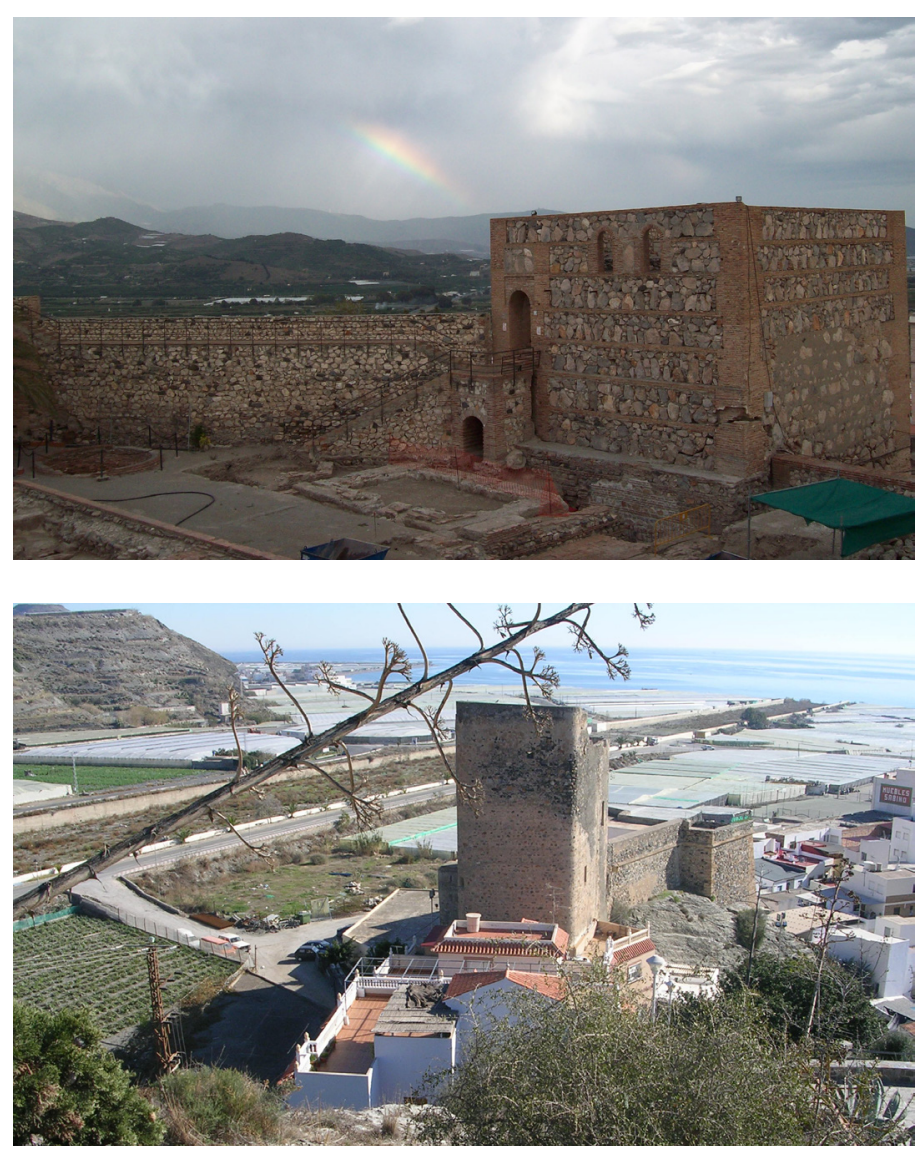

Torre del Diablo. Gualchos-Castell de Ferro (izquierda) | foto GESTO patrimonio cultural

Castillo de Salobreña (arriba) | foto Ana M. ${ }^{a}$ López

Castillo de La Rábita (abajo) | foto GESTO patrimonio cultural 
Vertebrado por ese río Guadalfeo, tiene, sin embargo, dos claros componentes físicos:

1. La llanura aluvial, que es una formación deltaica no suficientemente formada, pues cuenta con áreas encharcadas y el río tardó en fijar su cauce, hasta el extremo de que solo a partir de ya avanzada la segunda mitad del siglo XIX comenzó su encauzamiento creando una barrera de árboles para impedir que se produjesen desbordamientos. Naturalmente no era fácil de conseguir, dado el régimen mediterráneo del Guadalfeo. No obstante, al tratarse de una corriente con agua permanente, era posible emplearla para derivar acequias de riego y así desviar el agua por canales. Dos se documentan, la acequia de Salobreña, por la margen derecha, y la de Motril, por la izquierda. Así se evitaba que hubiese un flujo excesivo una vez que salía al área llana. Con todo, todavía en el siglo XVIII, en una representación gráfica muy ilustrativa, se puede apreciar cómo contaba con varios brazos el curso y, además, cómo se formaban charcas. Aun queda la llamada de Suárez, que es una zona húmeda de cierta importancia.

Las referencias a esta característica ya aparecen en época nazarí sin ningún género de dudas. La relación entre las fiebres causadas en la población por el anopheles, o sea, el paludismo, y las aguas estancadas es un hecho innegable.

Los asentamientos que hay en ese espacio llano están situados en elevaciones más o menos seguras en todas las épocas. En la medieval se aprecia ya conformado con los establecimientos situados en el tómbolo de Salobreña (la misma villa amurallada), en los extremos del delta (Batarna, en el Maraute) o en las colinas próximas.

2. Las áreas interiores que están organizadas en los cursos de agua que alimentan el bajo Guadalfeo, o incluso en la misma montaña. Se forman subconjuntos territoriales, algunos de los cuales son muy notables, como el que integran los asentamientos del Valle del río de la Toba.

La evolución histórica del poblamiento muestra la variable organización del territorio y enuncia los bienes patrimoniales que existen y dan la medida de su riqueza arqueológica.

Ante todo es muy claramente perceptible la crisis del Mundo Antiguo en el medio urbano o casi urbano, al igual que la ruptura que significa la ocupación árabe posterior. Así, en Salobreña, los materiales recuperados en el castillo y en el mismo casco urbano obligan a cifrar la ocupación árabe a partir del siglo X o, como muy pronto, a finales del siglo IX (GÓMEZ BECERRA, 1998a), en tanto que los del Peñón en el mar, que tiene restos de época neo- 
lítica hasta el siglo IV d. C., muestran un hiato hasta el siglo XII (ARTEAGA; NAVAS; RAMOS et àl., 1992).

Cabría preguntarse de manera inmediata si esta crisis trajo consigo un cambio en los mecanismos productivos $y$, por consiguiente, en los asentamientos y en la organización del territorio. A partir del siglo IV se aprecia la pérdida de entidad de las villae; su ruina es evidente, si bien se puede hablar de una perduración urbana hasta fechas ligeramente más tardías.

Hay un abandono de gran parte de las actividades hasta entonces relacionadas con la vida marítima, si bien no desaparecieron. Se observa un repliegue hacia el interior. Acerca de su entidad es muy poco lo que podemos decir, toda vez que sólo se conocen algunos asentamientos a través de una prospección general del territorio costero.

A los yacimientos situados en la misma Salobreña, tendríamos que añadir algunos otros de su entorno más o menos próximo, que nos permiten entender la evolución que venimos señalando. Son, por ejemplo, el Cerro del Vínculo, la Cuerda del Jaral y el Castillejo de Vélez Benaudalla. Su ocupación va desde el siglo VI en adelante. Los asentamientos andalusíes se identifican a partir del siglo IX, y aparecen ya formas de cultivo de las tierras basadas en la irrigación.

Sin duda, desde el siglo XI fue ganando en importancia el conjunto territorial, con dos áreas definidas, ya señaladas. La de la montaña se fue extendiendo hacia el este. Esta última, aparte de su valor agrario, mostró una gran capacidad ganadera.

A partir del siglo XII y, sobre todo, en tiempos nazaríes, el territorio medio de la costa se configuró como un espacio muy organizado desde Salobreña, único centro con ciertas características urbanas, capaz de concentrar una buena parte de la producción y de reexpedirla a partir de su puerto. El núcleo estaba coronado por una alcazaba, sede del poder real nazarí, que también tenía grandes propiedades territoriales, sobre todo plantaciones de caña de azúcar. La dinámica comercial fue esencial para darle entidad al conjunto y hacer destacar el asentamiento principal.

Esa gran fortaleza urbana sirvió de punto de apoyo para los castellanos tras su conquista, quienes reforzaron su carácter señorial en su tierra con asentamientos que se convirtieron en posesiones de los caballeros allí establecidos.

Paralelamente el monocultivo se fue imponiendo y el azúcar se convirtió en el proyecto principal. La Vega del Guadalfeo se plantó casi exclusivamente de caña y comenzó un período fabril de extraordinaria importancia que marcaría esta área durante toda la época moderna y alcanzaría a ver un auge

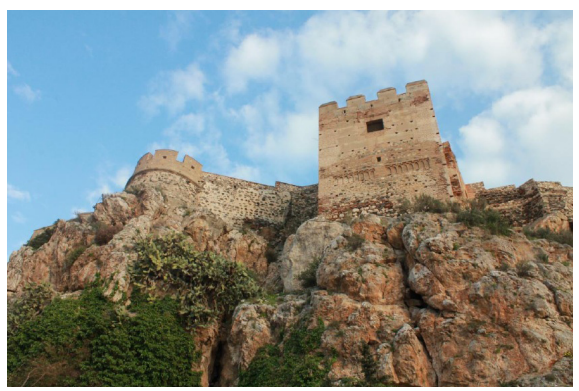

Castillo de Salobreña | foto Enrique Recio 
desmedido en la contemporánea, gracias a las fábricas de vapor. La cultura del azúcar está ampliamente representada en este espacio, siendo lamentable que no haya cuajado ningún programa de recuperación patrimonial.

$>$ El área más occidental presenta un perfil bastante recortado, pues la montaña llega al mismo borde del mar. Aparece una sucesión constante de calas; muchas de ellas pequeñas. La costa se abre en dos puntos concretos por llanuras de origen aluvial: Almuñécar y La Herradura. De la primera cabe decir que es doble, formada por sendos ríos, el Verde, a levante, y el Seco, a poniente. Entre ambos espacios llanos está un entrante de la montaña, que en realidad es la prolongación de una sierra que se inicia entre las cabecera de los dos ríos. Es en su extremo, sobre el litoral, donde está Almuñécar. La Herradura, por su parte, se halla entre la Punta de la Mona, por el este, y los acantilados de Cerro Gordo, y es fruto de los rellenos depositados por el río Jate.

Almuñécar ha sido el núcleo más importante de todo el conjunto costero desde tiempos muy antiguos. En época de las colonizaciones tuvo un papel muy destacado, sobre todo como factoría de garum. Se prolongó, junto con otros edificios de corte monumental, en tiempos romanos. En esos era un municipium, quedando huellas arqueológicas de primera magnitud, que han llegado hasta nosotros. Su valor patrimonial es muy elevado.

Se documenta arqueológicamente un hiato entre la ciudad tardoantigua, en una profunda crisis desde el siglo $\mathrm{V}$, y la andalusí, que no se conformará

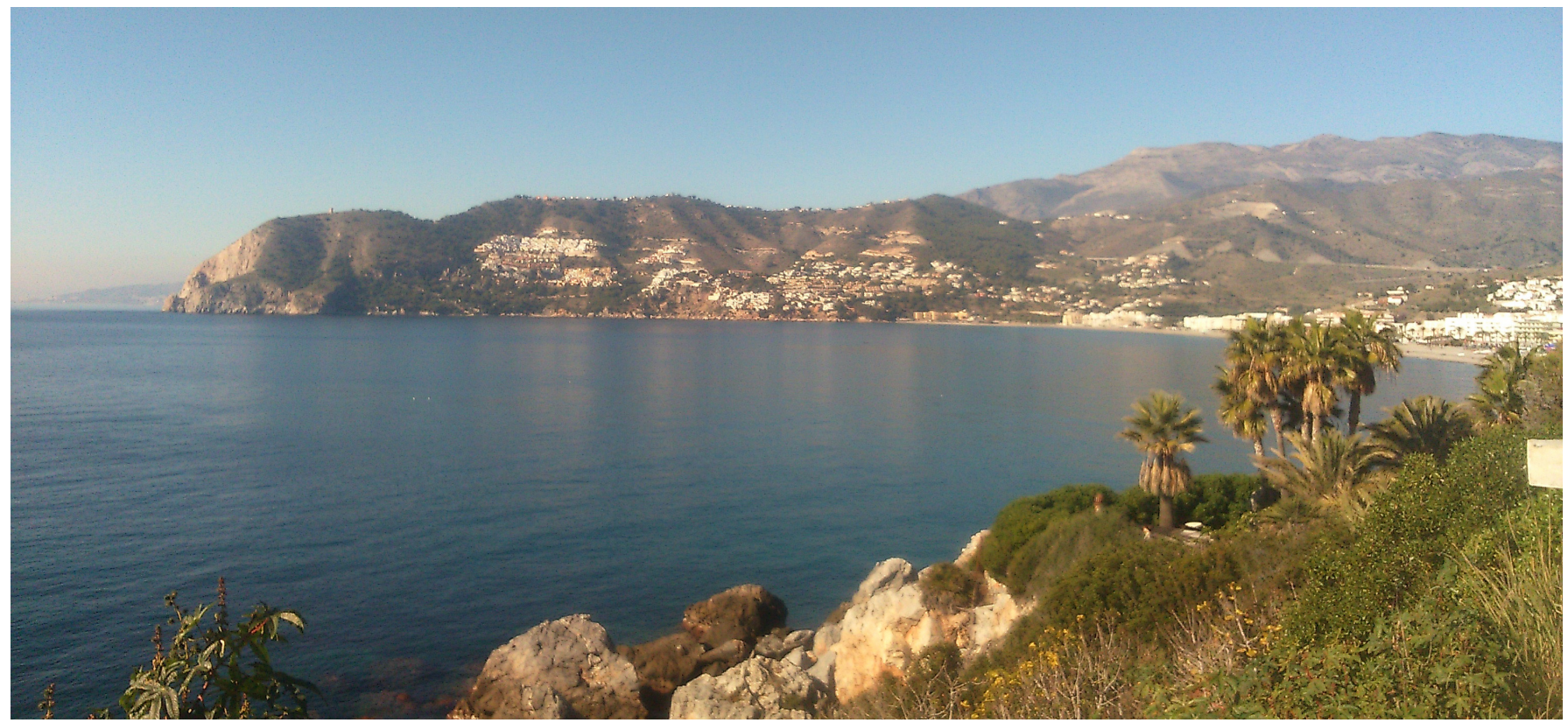


hasta el siglo IX y sobre todo en el siglo X. La lenta estructuración de la madīna viene dada por una conformación de los asentamientos rurales de su entorno. La prueba la tenemos otra vez en las fuentes escritas, porque el geógrafo del siglo XI al-'Ud̆ī menciona tres aŷzā' (plural de ŷuz') en el conjunto territorial de Almuñécar, en tanto que solo habla de un iqlīm en el de Salobreña. Esos tres tienen como cabeza un hișn, si bien en dos casos se puede hablar de asentamiento encastillados. Son los de šāț y Muškarīl, que se organizan a partir de estructuras defensivas que han sido identificadas.

La primera es la que se sitúa en el denominado Peñón de Los Castillejos². El hișn se levanta en una plataforma rocosa elevada y una altitud superior de $934 \mathrm{~m}$ e inferior de $800 \mathrm{~m}$. Restos de un amurallamiento quedan visibles en la parte sur y la central, en la más alta del conjunto. Dos aljibes, a distinta altura, se encuentran en este yacimiento. Fragmentos de cerámica y de tejas muestran una ocupación que no parece anterior al siglo IX, si bien lo es plenamente en el siglo $X$ y sucesivamente.

Moscaril, topónimo que ha pervivido, es un asentamiento que ocupa la cumbre del pico de ese nombre. Desde ella se domina visualmente gran parte de la costa y la ciudad de Almuñécar. Se halla en una elevación de una serie de crestas rocosas que separan la cuenca del río Verde, al este, de la del río Seco, al oeste. En época nazarí aún se conocía la existencia de restos materiales.

En cuanto a la propia Almuñécar cabe considerarla en el primer período andalusí como un hișn, a partir del cual, seguramente desde el siglo XI en adelante, se configuraría plenamente la ciudad.

La imagen de la madīna de Almuñécar que ha llegado hasta nosotros se refiere al período final del reino nazarí y se apoya en una fuente documental de primera magnitud, el Libro de Repartimiento de Almuñécar, que ha sido editado (CALERO PALACIOS, 1984: 401-533).

Fue un núcleo de gran importancia en el tráfico marítimo, porque el mar es fuente de riqueza pesquera, pero camino habitual para la salida y entrada de productos más o menos elaborados, pero con una fuerte y creciente demanda. Así, Almuñécar es puerto y mercado, asentamiento urbano rodeado de tierras fértiles y núcleos de población, fundamentalmente alquerías, capaces de producir para un mercado que se iba infiltrando e imponiendo sus condiciones. No obstante, los mecanismos de preservación de los asentamientos rurales existían y permitían que las unidades campesinas subsistieran sin graves alteraciones, al mismo tiempo que se aprecia una actividad especulativa por propietarios que pusieron, gracias a la vivificación (ihŷà), tierras destinadas a producir productos procedentes de los secanos, como los frutos secos (TRILLO SAN JOSÉ, 2002a; 2002b).
2

Una descripción pormenorizada y un análisis en GÓMEZ BECERRA, 1998b: 100-115. 


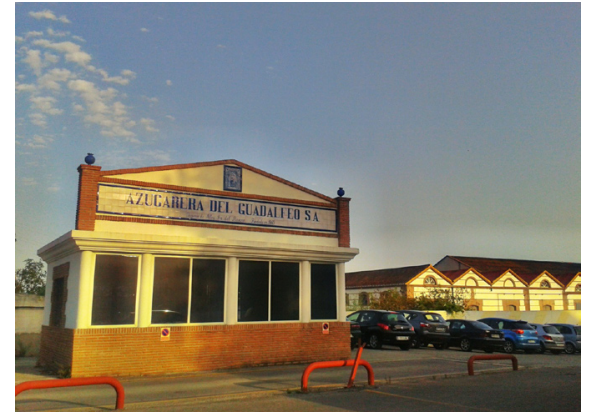

Azucarera del Guadalfeo | foto Isabel Rivera

Así pues, el valor comercial del territorio no se puede separar de la capacidad productiva que en época nazarí fue incrementada por elementos del propio núcleo con fines mercantiles e incluso por el propio sultán granadino (MALPICA CUELLO, 2009). La agricultura existe y da lugar al comercio, para, más tarde, ya en el período nazarí y aun antes, incidir este en ella, pero sin romperla de manera irreconocible, sino en un equilibrio a veces inestable.

La vida marítima, en su vertiente comercial, pero también pesquera, y la agrícola están unidas en la referencias en las fuentes escritas.

En el siglo XV hay plenamente configurado un centro de recepción de productos en Almuñécar e incluso tienen los genoveses capacidad de producir ellos mismos el azúcar en la aduana que había en la propia Almuñécar y que menciona el Libro de Repartimiento de Almuñécar (CALERO PALACIOS, 1984: 514).

Su espacio superior, en donde se halla la alcazaba, cobija restos de gran importancia que ponen de manifiesto la presencia de los reyes nazaríes. Su papel en el conjunto urbano y en el territorial es más que evidente.

Cuando se produce la conquista castellana, se convierte en el punto básico del control castellano de gran parte de la costa. La defensa del territorio en su conjunto está encomendada a su fortaleza, apoyada por la de Salobreña, al este, así como por una serie de torres que resguardan pequeñas calas. La vigilancia y la presión continuas eliminaron numerosos núcleos rurales, cuyas tierras de cultivo pasaron a una pequeña nobleza.

El cultivo de la caña de azúcar fue el más importante de todos y la industria azucarera se sobredimensionó. No obstante, la riqueza del azúcar no ha dejado una huella tan perdurable como en el delta del Guadalfeo. Hoy solo resta un paisaje de subtropicales y de un centro de vacaciones.

En suma, la costa de Granada guarda un paisaje cultural de gran belleza en el que se reconocen las diferentes etapas históricas. Se trata de un patrimonio de primera magnitud, en el que se incluyen restos arqueológicos de todas las épocas que nos hablan muy claramente de la importancia de esta bella tierra abierta al mar y, por tanto, a todas las influencias exteriores procedentes del Mediterráneo, que es la vía principal de comunicación y articulación del espacio.

Los vestigios de todas las épocas permiten hacer una lectura amplia y clara de la historia de este territorio, y hacen posible documentar su devenir histórico, con momentos notables como los de las colonizaciones, el Imperio romano, el período andalusí y las transformaciones castellanas, hasta llegar a un siglo XVIII que desarrolla esta zona y al XIX, en donde la eclosión de la industria azucarera aún ha marcado el conjunto. 


\section{BIBLIOGRAFÍA}

- ARTEAGA, O.; NAVAS, J.; RAMOS, J. F. et àl. (1992) Excavación de urgencia en el peñón de Salobreña. Salobreña: Ayuntamiento, 1992

- CAlero palacios, M. C. (1984) El manuscrito de Almuñécar: Libro de Apeos del Archivo de la Diputación Provincial de Granada. Almuñécar. Arqueología e Historia, II, 1984, pp. 401-533

- Gómez BECERRA, A. (1998a) Cerámica islámica de Salobreña. Salobreña: Asukaria Mediterranea, S.L. Servicios De Cultura, 1998

- GÓmez BECERRA, A. (1998b) El poblamiento altomedieval en la costa de Granada. Granada: Azucaría mediterránea, 1998

- MALPICA CUELLO, A. (2009) Las "tierras del rey" y las ordenanzas de la acequia del río Verde en Almuñécar. En VAL VALDIVIESO, I. (DEL); MARTÍNEZ SOPENA, P. (eds.) Castilla y el mundo feudal: homenaje al profesor Julio Valdeón, vol. 2. Valladolid: Junta de Castilla y León, Consejería de Cultura y Turismo; Universidad de Valladolid, 2009, pp. 167-178

- TRILLO SAN JosÉ, C. (2002a) Contribución al estudio de la propiedad de la tierra en época nazarí. En TRILLO SAN JOSÉ, C. (ed.) Asentamientos rurales y territorio en el Mediterráneo medieval. Granada: Athos Pergamos Ediciones, 2002, pp. 499-535

- TRILlo SAN JOSÉ, C. (2002b) La propiedad de la tierra en el reino nazarí de Granada: Almuñécar y su espacio agrario. En REGLERO DE LA FUENTE, C. (ed.) Poder y sociedad en la Baja Edad Media hispánica. Estudios en homenaje al profesor Luis Vicente Díaz Martín. t. II. Valladolid: Universidad de Valladolid, Secretariado de Publicaciones e Intercambio Editorial, 2002, pp. 1149-1187 